\title{
Big brains on the small screen
}

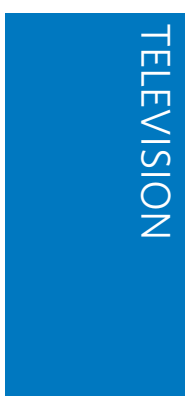

Super Bowl ads aren't traditional turf for scientific icons. American football's annual showdown commands a viewership of well over a hundred million, so mid-game advertising rates - and expectations are high. But this year's Super Bowl featured a bare-foot Geoffrey Rush posing as Albert Einstein, belting out a Lady Gaga cover on the violin. The ad was for the National Geographic Channel's new series Genius and the message was clear: scientists can be every bit as entertaining as quarterbacks.

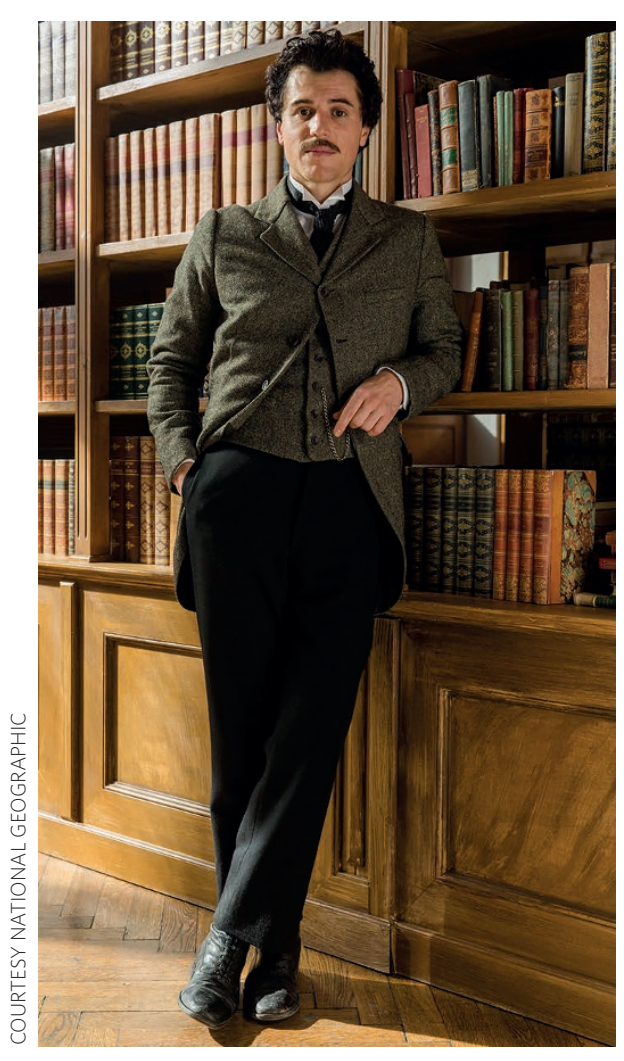

Einstein is the first genius to appear in the new series - his story arcs across a ten-part season in what promises to be an ongoing journey into the lives of the greats. And as for much of what graces the small screen these days, National Geographic has assembled a star-studded creative team. Rush plays the latter-day hero, Emily Watson his long-suffering wife, the enigmatic Johnny Flynn a youthful

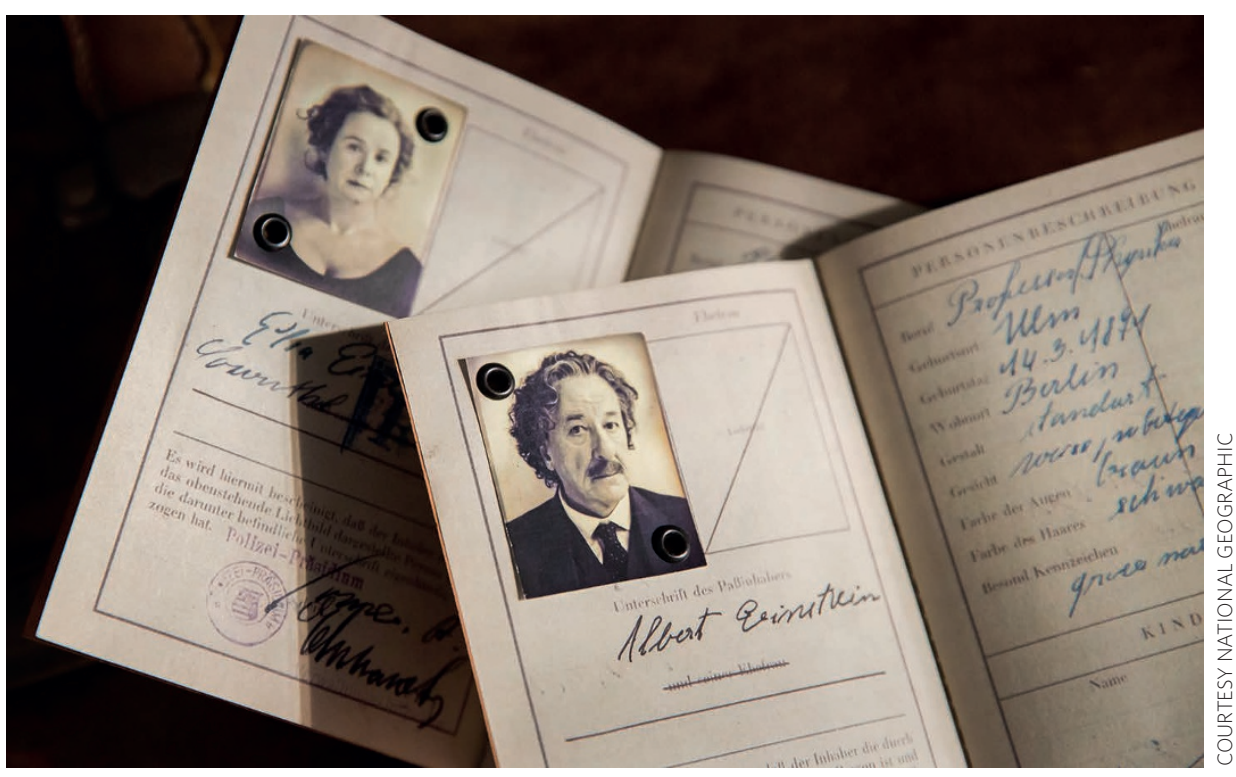

Albert, and Ron Howard takes an executive producer role and directs the first episode.

The series transforms Einstein from demigod into human. Lady Gaga doesn't get another look-in - the story stays true to its time - but she's there in spirit. Einstein is sassy, he is flawed. He's steadfast in the belief that monogamy "is a construct of religious authority" and debuts in the pilot with some boisterous adultery up against the blackboard in his office. Ultimately this is the hook for the uninitiated: you've heard about Einstein, the mind, now meet Einstein, the man.

Howard lets the pilot unfold in what could only ever be a nonlinear narrative. "The distinction between the past, present and future is but a stubborn illusion," intones Rush to a captive young audience of aspiring physicists in Berlin. And this could very well serve as the motto for the series. We skip between a youthful Einstein in the late nineteenth century, dropping out of school, failing his entrance exam for Zurich Polytechnic, to an older Einstein at the height of his influence, struggling with an increasingly hostile political climate.

Fresh from his role as the despotic head of the Bolton clan in Game of Thrones, Michael McElhatton gives a stirring performance as Philipp Lenard, Einstein's most vocal detractor. In a rousing speech, he cites Einstein's war against reason, his disdain for empirical evidence. "Germany and German physics are under threat," he proclaims, calling on his audience to "protect our Aryan respect for empirical observation.”

Indeed, Einstein's Gedankenexperimente play their own role in the series - they're almost a gift to the show's creators. And his politics are diametrically opposed to Lenard's. He casts nationalism as an "infantile disease", and rejoices when he formally sheds his German citizenship and becomes stateless after moving to Switzerland. "Now you are a citizen of the world," he is told, a sentiment with which certain world leaders would vehemently disagree.

There is much to learn from this point in history and the creative team behind Genius are adept at drawing the parallels for us. Fritz Haber appears in 1922, chastising Einstein for worrying about Hitler's rising popularity. "Adolf Hitler is a loudmouth art-school reject with a handful of supporters in a nation of 60 million," he says. "He'll be gone in a year."

The familiarity of this particular brand of optimism is jarring - and ultimately rather depressing. As the Einsteins make preparations to flee pre-war Germany in the final scenes of the pilot, one wonders whether a similar drain will affect parts of the world currently beset by a nationalism that interferes with scientific progress.

\section{REVIEWED BY ABIGAIL KLOPPER}

Genius began on 25 April 2017 on the National Geographic Channel. 